\title{
Differential effects of interleukin-I $\beta$ and SIOOB on amyloid precursor protein in rat retinal neurons
}

\author{
Peter JB Anderson' \\ Helena R Watts' \\ Sheila Jen' \\ Stephen M Gentleman ${ }^{2}$ \\ Juliet A Moncaster' \\ D T Walsh' \\ Ling-Sun Jen' \\ 'Department of Cellular \\ and Molecular Neuroscience \\ and ${ }^{2}$ Department of Clinical \\ Neuroscience, Division of \\ Neuroscience and Mental Health, \\ Imperial College London, Burlington \\ Danes Building, Hammersmith \\ Hospital, London, UK
}

Correspondence: Peter JB Anderson Department of Cellular and Molecular Neuroscience, Division of Neuroscience and Mental Health, Imperial College London, Burlington Danes Building, Hammersmith Hospital, 160 Du Cane Road, London, WI2 ONN, UK Email peter.anderson@imperial.ac.uk
Purpose: Interleukin-1 $\beta$ (IL-1 $\beta$ ) and S100B calcium binding protein B (S100B) have been implicated in the pathogenesis of Alzheimer's disease. Both are present in and around senile plaques and have been shown to increase levels of amyloid precursor protein (APP) mRNA in vitro. However, it is not known how either of these substances affects APP in vivo.

Methods: We have studied the effects of IL-1 $\beta$ and S100B on the expression and processing of APP using a retinal-vitreal model. We have also investigated the effect of amyloid beta peptide $(A \beta)$ on APP in the same system and the regulation of S100B production by $A \beta$ and IL-1 $\beta$ from retinal glial cells.

Results: Retinal ganglion cells constitutively express APP. However, after intravitreal injection of IL- $1 \beta$ or A $\beta$ there was a marked reduction in APP levels as detected by Western blotting and IL- $1 \beta$ produced a decrease in APP immunoreactivity (IR). Nissl staining showed that the integrity of the injected retinas was unchanged after injection. Two days after S100B injection, there was a small reduction in APP-IR but this was accompanied by the appearance of some intensely stained large ganglion cells and there was some up-regulation in APP holoprotein levels on Western blot. Seven days post-S100B injection, these large, highly stained cells had increased in number throughout the retina. Injection of $A \beta$ and IL-1 $\beta$ also caused an increase in S100B production within the retinal Müller glial cells.

Conclusion: These results support the hypothesis that S100B (a glial-derived neurotrophic factor) and IL-1 $\beta$ (a pro-inflammatory cytokine) can modulate the expression and processing of APP in vivo and so may contribute to the progression of Alzheimer's disease.

Keywords: Alzheimer's disease, interleukin $1 \beta, \mathrm{S} 100 \mathrm{~B}$, amyloid precursor protein, amyloid- $\beta$, retina

\section{Introduction}

The neuropathological hallmarks of Alzheimer's disease (AD) are senile plaques and neurofibrillary tangles. The plaques are comprised of a variety of peptides, the most abundant of which is amyloid beta peptide $(\mathrm{A} \beta)$ and it is thought the abnormal cleavage of amyloid precursor protein (APP) by $\beta$ - and then $\gamma$-secretase yields this pro-aggregatory A $\beta$ peptide (Hardy 1997). These plaques are intimately associated with activated microglial cells interdigitating the plaques and astrocytes surrounding the plaques. It has been shown that these cells over-express pro-inflammatory factors such as S100B and interleukin-1 beta (IL-1 $\beta$ ) (Griffin et al 1995; Mrak et al 1996).

$\mathrm{S} 100 \mathrm{~B}$ is a small $10 \mathrm{kDa}$ protein belonging to the EF-hand family of calcium binding proteins and is released from astrocytes and Schwann cells (Donato 2001). At lower doses (high picomolar to low nanomolar), S100B displays neurotrophic properties by increasing neuronal survival and promoting neurite outgrowth (Kligman et al 1985; Bhattacharyya et al 1992). However, at higher doses, S100B stimulates astrocytes and microglia to produce pro-inflammatory cytokines including IL-1 $\beta$ (Kim et al 2004). Studies from Sheng and colleagues (1996) suggest that early plaques are accompanied by large numbers of astrocytes expressing S100B whilst at later stages there are far 
fewer S100B-positive astrocytes, implying a role for this factor in early plaque development. This is further supported by evidence showing that in the APP-over expressing mouse, APPV717F mice, increased levels of S100B precede the deposition of $A \beta$ (Sheng et al 2000). Whether S100B causes a direct increase in $\mathrm{A} \beta$ production or whether it is a secondary increase remains to be determined.

Interleukin-1 $\beta(17 \mathrm{kDa})$ is a pro-inflammatory cytokine having a multitude of different actions. Microglial cells within senile plaques have been shown to increase their production of IL-1 $\beta$ and this expression increases with plaque pathology; finally disappearing at the end stage "burnt-out" plaques (Mrak and Griffin 2001). Again, it would appear that IL- $1 \beta$ may be involved in production of $A \beta$, but whether it is cause or effect is still unclear. IL- $1 \beta$ increases the expression of APP mRNA in cultured cells by acting on its promoter (Goldgaber et al 1989; Buxbaum et al 1992) and may regulate the increase in APP expression after traumatic brain injury (Ciallella et al 2002). Accumulation of APP may lead to increased production of $A \beta$ - the central core of amyloid plaques. Increased $A \beta$ could then cause the stimulation of glial cells resulting in further expression of S100B. S100B may stimulate the release of IL- $1 \beta$ from microglia and so a "cytokine cycle" is initiated, perpetuating the damage (Griffin et al 1998). However, the direct actions of S100B and IL-1 $\beta$ on APP production and processing in vivo are unclear. To address this issue, we have used a rat retinal-vitreal model to study the effects of these cytokines on APP expression in vivo. This is a potentially useful model because retinal ganglion cells (RGC) constitutively express APP (Morin et al 1993) and the closed nature of the system means that the injected substances remain in situ rather than being rapidly cleared, giving them the opportunity to act locally. Furthermore, the retina contains most of the nerve cells that express AD-associated molecules, all the major neurotransmitter-producing neurons and most of the glial populations found in the brain (Guo et al 1991, 1992a, 1992b; Yang et al 1992; Chen et al 1996; Bresciani et al 2002; Walsh et al 2005; Watts et al 2007), thus enabling us to study the interplay of these cytokines within a central nervous system setting.

\section{Materials and methods}

All experimental procedures were carried out in accordance with the Animals (Scientific Procedures) Act 1986. Female Sprague-Dawley rats (6-8 weeks old) were anaesthetised with sodium pentobarbital $(0.6 \mathrm{ml} / 100 \mathrm{~g})$ and underwent unilateral intravitreal injection with either S100B (Sigma, UK; 2 and $5 \mathrm{nmol}$ in $3 \mu \mathrm{l}$ vehicle; $\mathrm{n}=6$ per dose); rat recombinant
IL-1 $\beta$ (Serotec, UK; 150 and $1500 \mathrm{U}$ in $3 \mu \mathrm{l} ; \mathrm{n}=9$ per dose), the higher dose based on a study by Bamforth and colleagues (1997); aggregated $A \beta_{1-42}$ (Bachem, UK; 2 nmol in $3 \mu \mathrm{l}$; $\mathrm{n}=12)$ or phosphate-buffered saline (PBS) $(n=6)$. $A \beta_{1-42}$ was aggregated by incubation at $37{ }^{\circ} \mathrm{C}$ for 4 days in $\mathrm{PBS}$ (Jen et al 1998; Walsh et al 2002). Before injection, some of the vitreous humour was removed to avoid increased intraocular pressure. At 2 and 7 days after injection, animals were either killed by cervical dislocation and the retinas removed for Western blotting or they were transcardially perfused with saline followed by $4 \%$ paraformaldehyde (PFA) and processed for immunohistochemistry (IHC; $n=3$ for each treatment). $A \beta_{1-42}$-injected animals were killed at 2 days.

For Western blotting ( $\mathrm{n}=3$ for each treatment), retinas were rapidly removed and snap frozen in liquid nitrogen. Retinas were homogenised in RIPA buffer (150 mM NaCl, $1 \%$ NP-40, $0.5 \%$ sodium deoxycholate, $0.1 \%$ SDS, in $50 \mathrm{mM}$ Tris, $\mathrm{pH}$ 8.0). A cocktail of protease inhibitors (CompleteMini ${ }^{\mathrm{TM}}$, Roche) was always added fresh to the lysis buffer to avoid nonspecific digestion of proteins. Retinal homogenates (30 $\mu \mathrm{g} /$ lane) underwent electrophoresis on $4 \%-12 \%$ BisTris gels (NuPAGE System, Invitrogen) and were then blotted onto nitrocellulose membranes. Blots were blocked in 5\% dried skimmed milk in PBS/0.1\% Tween 20 (blocking buffer) for at least 1 hour prior to incubation with either CT695 anti-APP antibody (Zymed, Laboratories Inc, USA; 1:200 dilution) or anti-S100B antibody (Sigma Chemical Company Ltd, Poole, UK; 1:1000 dilution) overnight at $4{ }^{\circ} \mathrm{C}$. Blots were washed and then incubated for 1 hour with peroxidase-conjugated anti-rabbit antibody (Sigma Chemical Company Ltd, Poole, UK; 1:3000) in blocking buffer. Bound immunoglobulins were detected with the ECL system. Some blots were stripped of the antibodies using ReBlot ${ }^{\mathrm{TM}}$ (Chemicon, Harrow, UK) and then re-probed with alphaactin antibody (Roche, Lewes, UK; 1:2000) to visualize the protein load per lane.

For IHC, eyes were removed, post-fixed in 4\% PFA (4 h) and sunk in sucrose overnight. The eyes were then embedded in OCT and frozen in isopentane pre-cooled in liquid nitrogen. Sections were cut at a $20 \mu \mathrm{m}$ thickness and mounted onto SuperFrost ${ }^{\circledR}$ Plus slides (VWR International). Sections were washed in $0.1 \mathrm{mM} \mathrm{PBS} / 0.3 \%$ Triton X-100 (Sigma, UK); endogenous peroxidases were blocked with $\mathrm{H}_{2} \mathrm{O}_{2}$ in methanol; and microwaved in EDTA, at 40\% power for $4 \mathrm{~min}$. Sections were then blocked in normal serum before addition of the primary antibody overnight, either CT695 anti-APP (1:1000 dilution) or anti-S100B (1:1000 dilution). Sections were washed and incubated with biotinylated secondary antibody 
(Vector, Peterborough, UK) for 45 minutes followed by further washing and incubation in Vectastain Elite $\mathrm{ABC}$ kit for 45 minutes (Vector, Peterborough, UK). Staining was visualized using the diaminobenzidine (DAB) peroxidise substrate kit (Vector, Peterborough, UK). APP-staining also included nickel enhancement. For staining with anti-S100B antibody, the microwave step was omitted. Sections were dehydrated in an increasing alcohol gradient, cleared in xylene and mounted with DPX resin (BDH Chemicals Ltd, Poole, UK).

For Nissl staining to reveal the cytoarchitecture, sections were stained with cresyl fast violet (Raymond A Lamb, Eastbourne, UK) for 5 minutes, washed in PBS and dehydrated in an increasing alcohols gradient and mounted with DPX.

\section{Results}

\section{APP immunoreactivity is altered by IL-I $\beta$ and SIOOB}

We have set out to address how APP processing is affected by IL- $1 \beta$ and $\mathrm{S} 100 \mathrm{~B}$ in projection neurons of the rat retina. In control animals, APP, as detected with a C-terminal directed antibody (CT695, Zymed), is constitutively expressed in the RGC throughout the ganglion cell layer with some staining seen in the axons of these cells. This pattern of staining was unchanged by intravitreal injection of PBS at 2 days (Figure $1 \mathrm{a}$ and $\mathrm{b}$ ) or by injection of the lower dose of IL-1 $\beta$ (150 U/3 $\mu 1$, not shown) and S100B (2 nmoles/3 $\mu 1$, not shown). However, 2 days after intravitreal injection with higher dose IL-1 $\beta(1500 \mathrm{U} / 3 \mu \mathrm{l})$ there was a marked decrease in immunoreactivity (IR) throughout the ganglion cell layer with loss of staining in the RGC (Figure 1c). In the retinas injected with a higher dose of $\mathrm{S} 100 \mathrm{~B}(5 \mathrm{nmol} / 3 \mu \mathrm{l})$, there appeared to be a small decrease in the overall staining within the ganglion cell layer but this was accompanied by the appearance of a small number of ganglion cells that showed very strong APP-IR (Figure $1 \mathrm{~g}$ and $\mathrm{h}$ ). Seven days after injection with $\mathrm{S} 100 \mathrm{~B}$, the number of these intensely stained RGCs appeared to increase (Figure 1i and j). Similar large, heavily stained cells also became apparent 7 days after injection with high dose IL-1 $\beta$ (Figure 1e and $\mathrm{f}$ ). As the injected $A \beta_{1-42}$ cross-reacted with the CT695 antibody, we were unable to ascertain the changes in APP-IR after injection of the peptide. Since we only noted changes with the higher doses of cytokines tested, we continued to use these doses for further studies.

To ensure that our injection procedures were not depleting cells within the granule cell layer (GCL), we looked at Nissl staining of sections injected with PBS, IL-1 $\beta$, and
$\mathrm{S} 100 \mathrm{~B}$. The staining revealed that there was no change in the cytoarchitecture of the retinas after injection with S100B and we could not detect any pyknotic bodies. After injection with IL-1 $\beta$, there was the appearance of a cellular infiltrate in some of the injected animals but the cells within the GCL appeared healthy with no sign of pyknotic bodies (Figure 2).

\section{Differential effects of IL-I $\beta$, SIO0B, and $A \beta_{1-42}$ on APP processing}

We have used IHC to look at the cellular profile of APP changes but this does not allow us to study its processing. We therefore used Western blotting to investigate how each cytokine affected the processing of APP. Using the same antibody in the Western blots, APP appears as a cluster of bands at $98 \mathrm{kDa}$ and a single band at $54 \mathrm{kDa}$, as shown previously (Croucher et al 2003). Two days after injection with IL-1 $\beta$ or $A \beta_{1-42}$ there was a marked decrease in the $54 \mathrm{kDa}$ band in the injected as compared with noninjected eyes (Figure 3a and Figure 3c, respectively) and a decrease in the $98 \mathrm{kDa}$ band after $A \beta_{142}$ (Figure $3 \mathrm{c}$ ). After injection with $A \beta_{142}$ there was also the appearance of lower molecular weight bands at around $13 \mathrm{kDa}$ and a band at approx $82 \mathrm{kDa}$ (Figure 3c). Interestingly, we were not able to detect the same band pattern in retinas from eyes injected with S100B, even though there was an up-regulation of the $98 \mathrm{kDa}$ band (Figure 3b). Figure $2 \mathrm{~b}$ also shows faint band fragments at approximately $30 \mathrm{kDa}$ and at $37 \mathrm{kDa}$ in injected and noninjected eyes. Seven days after injection of IL-1 $\beta$, the 98 and $54 \mathrm{kDa}$ bands had returned to the same levels as the noninjected eyes (not shown). Again, seven days after S100B injection, there was no difference in the levels and band pattern of APP between injected and noninjected eyes (not shown).

\section{SIOOB is up-regulated by $A \beta_{1-42}$ and IL-I $\beta$ in vivo}

As S100B appeared to be up-regulating APP expression in a sub-population of the RGCs and has been implicated in AD, we wanted to see how this cytokine is itself regulated by IL-1 $\beta$ and $A \beta_{1-42}$. In naïve, untreated retinas, $\mathrm{S} 100 \mathrm{~B}$ is constitutively expressed in the Müller glial cell end feet in the ganglion cell layer (Figure 4a). Injection of PBS caused a slight increase in S100B staining (Figure $4 \mathrm{~b}$ ). After injection with aggregated $\mathrm{A} \beta_{1-42}(2 \mathrm{nmol} / 3 \mu \mathrm{l}, 2$ days post-injection) there was a marked up-regulation of S100B in the Müller cell end feet and also the Müller cell bodies within the inner nuclear layer as well as the appearance of staining throughout the Müller cell radial processes (Figure 4c). Interestingly, we also noted an increase 


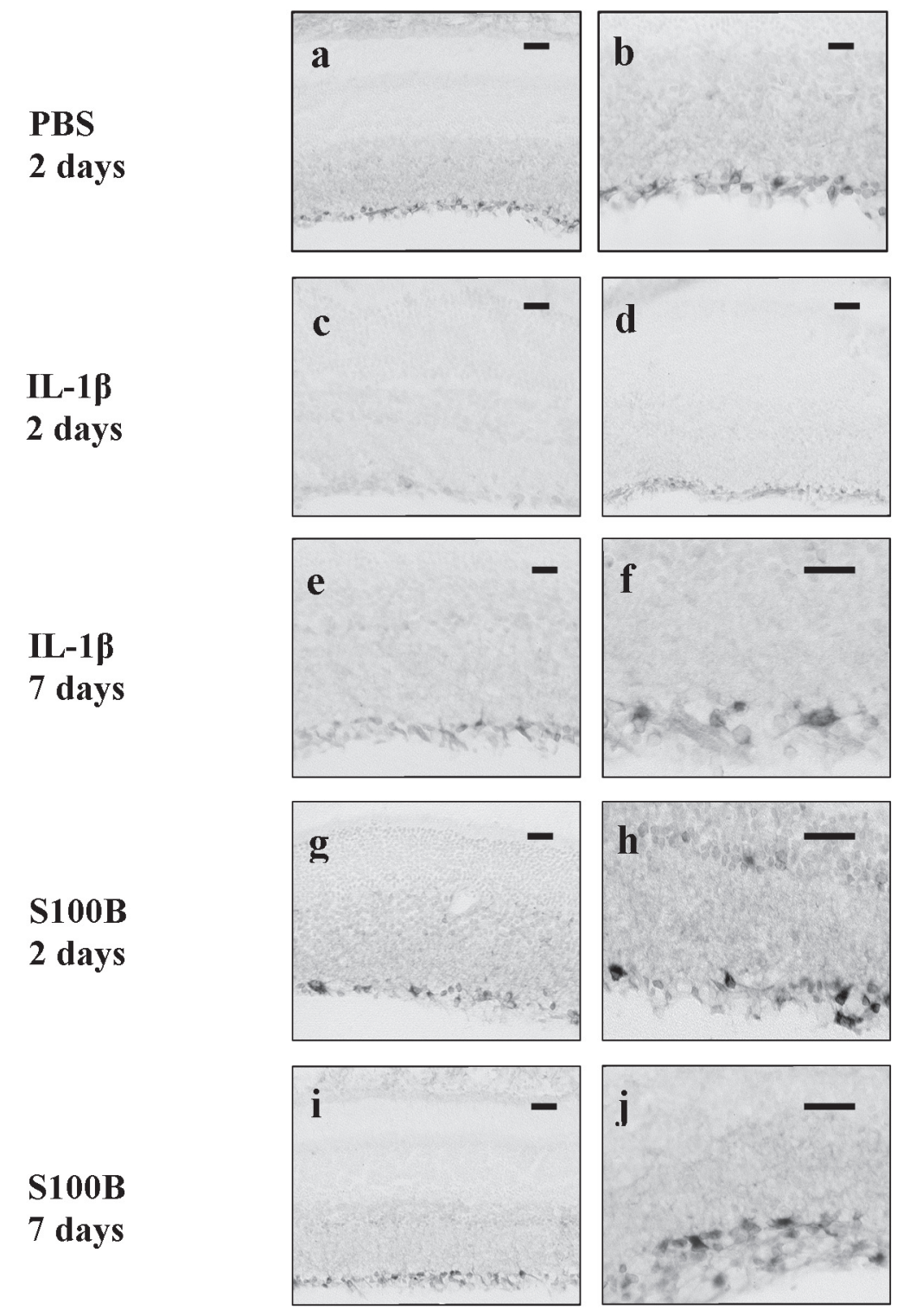

Figure I Photomicrographs showing APP immunoreactivity in rat retinas 2 days post-PBS injection at low (a) and high (b) magnification. Note staining is seen in the GCL with some axonal staining. Low magnification photomicrograph showing that APP immunoreactivity is decreased in retinas injected with IL-I $\beta$ after 2 days (c) compared with low magnification micrograph the retina from the corresponding noninjected eye (d). Low (e) and high (f) magnifications of retinas 7 days post-IL-I $\beta$ injection show recovery of APP staining of RGCs. Low and high magnifications of retinas 2 days post-SI00B injection show sporadic RGCs strongly stained for APP. Low (i) and high (j) magnifications of retina 7 days post-SIOOB injection indicating an increase in RGC immunoreactivity. Note: Scale bar $=50 \mu \mathrm{m}$.

Abbreviations: APP, amyloid precursor protein; GCL, granule cell layer; IL, interleukin; RGC, retinal ganglion cells; PBS, phosphate-buffer solution.

in S100B staining in the contralateral retina (not shown). Western blotting with an anti-S100B antibody showed the appearance of a strong band around $15 \mathrm{kDa}$, corresponding to $\mathrm{S} 100 \mathrm{~B}$ after injection with $\mathrm{A} \beta_{1-42}$ (Figure $4 \mathrm{e}$ ). The $7 \mathrm{kDa}$ band seen in lanes loaded with recombinant S100B probably represents the monomer, whereas the $15 \mathrm{kDa}$ band in the left (injected) eye probably represents the biologically active homodimer of S100B. There was no increase in S100B staining 2 days after injection of IL- $1 \beta$ (data not shown). However, there was a marked increase in S100B in the Müller glial cells 7 days after injection of IL-1 $\beta$ (Figure $4 d$ ) and, again, we noted a contralateral effect with increased S100B in the noninjected eye (data not shown).

\section{Discussion}

This study has highlighted the differential effects of two amyloid plaque-associated factors and $A \beta_{1-42}$ on the expression and processing of APP. Injection of IL- $1 \beta$ resulted in the reduction of APP-IR in RGCs and, along with injection of $A \beta_{1-42}$, a reduction on Western blot. However, injection of 

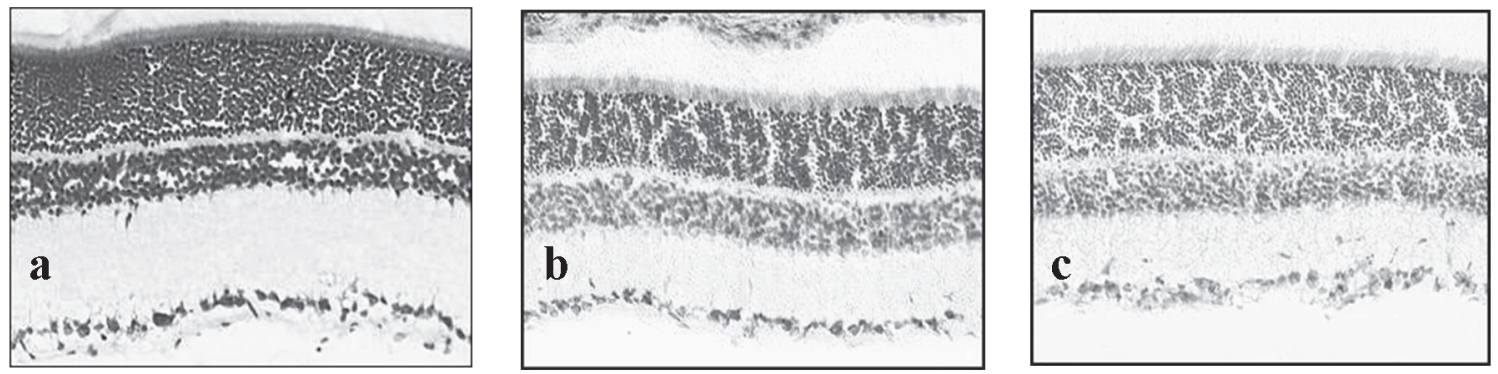

Figure 2 Nissl staining of (a) normal retina, (b) retina 2 days after injection with SI00B and (c) retina 2 days after injection with IL-I $\beta$. Note that the tissue architecture is not affected by the injection and that the GCL layer appears intact without loss of the large ganglion cells.

Abbreviations: GCL, granule cell layer; IL, interleukin.

S100B appears to increase APP levels in a population of the RGC (Figure 1 $\mathrm{g}-\mathrm{j}$ ) and an up-regulation of the $98 \mathrm{kDa}$ APP band (Figure $3 \mathrm{~b}$ ) as well as the appearance of faint protein bands at approximately $30 \mathrm{kDa}$ and $37 \mathrm{kDa}$.

The reduction in APP induced by IL-1 $\beta$ and $A \beta_{1-42}$ appears to be widespread throughout the ganglion cell layer. The reason for this APP down-regulation is unclear but it may be that it is a stress response of the peptide itself. In vivo, it has previously been demonstrated that some cytokines can down-regulate APP as well as the anti-apoptotic protein, Bcl-2, levels in the rat retina (Chen et al 1999). This appears to contradict studies that have shown that IL- $1 \beta$ can increase mRNA for APP (Goldgaber et al 1989; Buxbaum et al 1992), but may reflect the differences between the in vitro and in vivo systems. Whether we are observing a decrease in the production of APP, an increase in metabolism or both remains to be fully established, but we have observed, particularly after $A \beta_{1-42}$ injection, lower molecular weight bands that may represent breakdown products. In vitro evidence has shown that IL-1 $\beta$ alone and in combination with other cytokines can induce the production of soluble APPs (sAPPs) or $\alpha$-cleaved APPs ( $\alpha$ APPs) from a neuronal cell line stably transfected with APP. In combination with interferon- $\gamma$, there was also an increase in secreted $A \beta$ peptides in the same system (Sastre et al 2003). These changes occurred in the absence of a change in the cell-associated APP levels and so are likely to be a direct consequence of APP processing.

The APP band pattern produced in the retinas exposed to $A \beta_{1-42}$ is of particular interest since it appears similar to that of retinas exposed to the broad spectrum metabotropic glutamate (mGlu) receptor agonist, (1S,3R)-1-aminocyclopentane-1,3-dicarboxylic acid ((1S,3R)-ACPD) (Croucher et al 2003). The APP fragment that appears between the $98 \mathrm{kDa}$ holoprotein and the $54 \mathrm{kDa}$ fragment may be an $82 \mathrm{kDa}$ non-amyloidogenic soluble fragment (sAPP) formed from metabolism of APP by $\alpha$-secretase leading to proteolyic cleavage within the $A \beta$ region (Figure $3 \mathrm{c}$ ). Croucher and colleagues (2003) also demonstrated that fragments of APP metabolism can be secreted into the vitreous fluid of rat eyes after stimulation with this mGlu receptor agonist and, in view

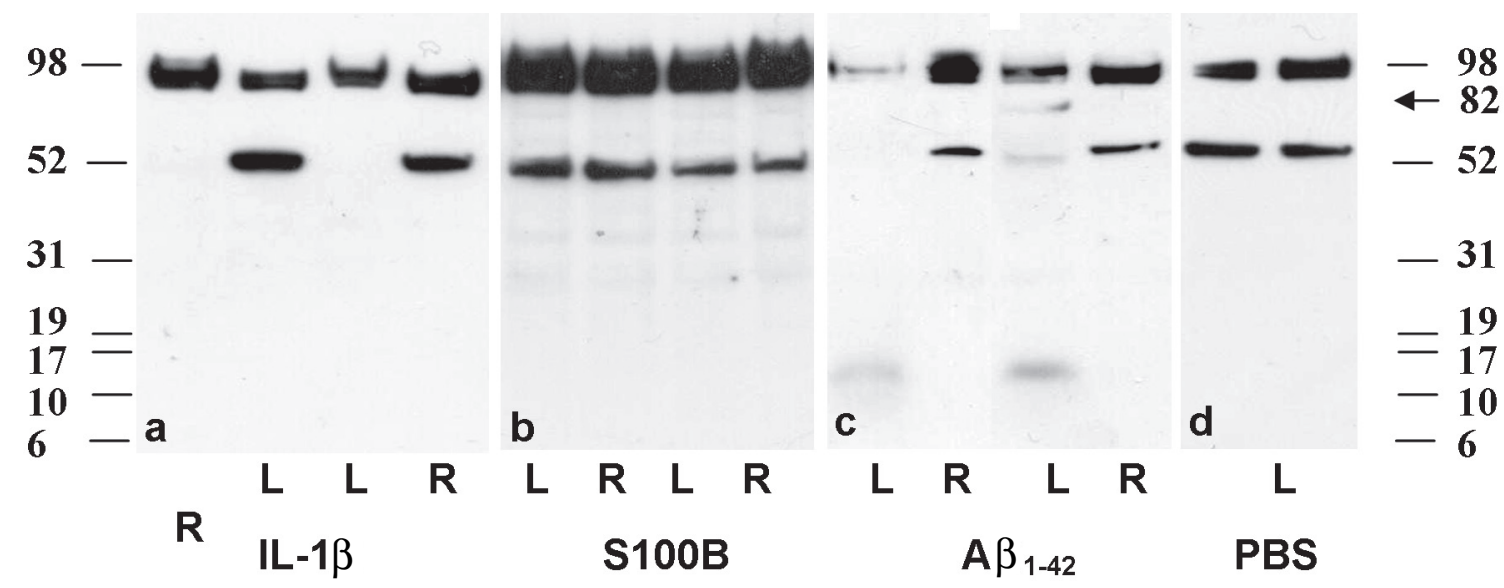

Figure 3 Western blotting of APP in retinas injected with (a) IL-I $\beta$, (b) SI00B, (c) A $\beta_{1-42}$ peptide, and (d) PBS 2 days after injection. Each panel shows 2 animals per treatment. Both IL-I $\beta$ and $A \beta_{1-42}$ show a marked reduction in APP levels in the injected left eye (L) compared with the noninjected right eye (R), particularly in the $54 \mathrm{kDa}$ band. There was no down-regulation after injection with SI00B or PBS. Note also the appearance of bands around $13 \mathrm{kDa}$ and $82 \mathrm{Kda}$ after injection with A $\beta_{1-42}$.

Abbreviations: APP, amyloid precursor protein; IL, interleukin; PBS, phosphate-buffer solution. 

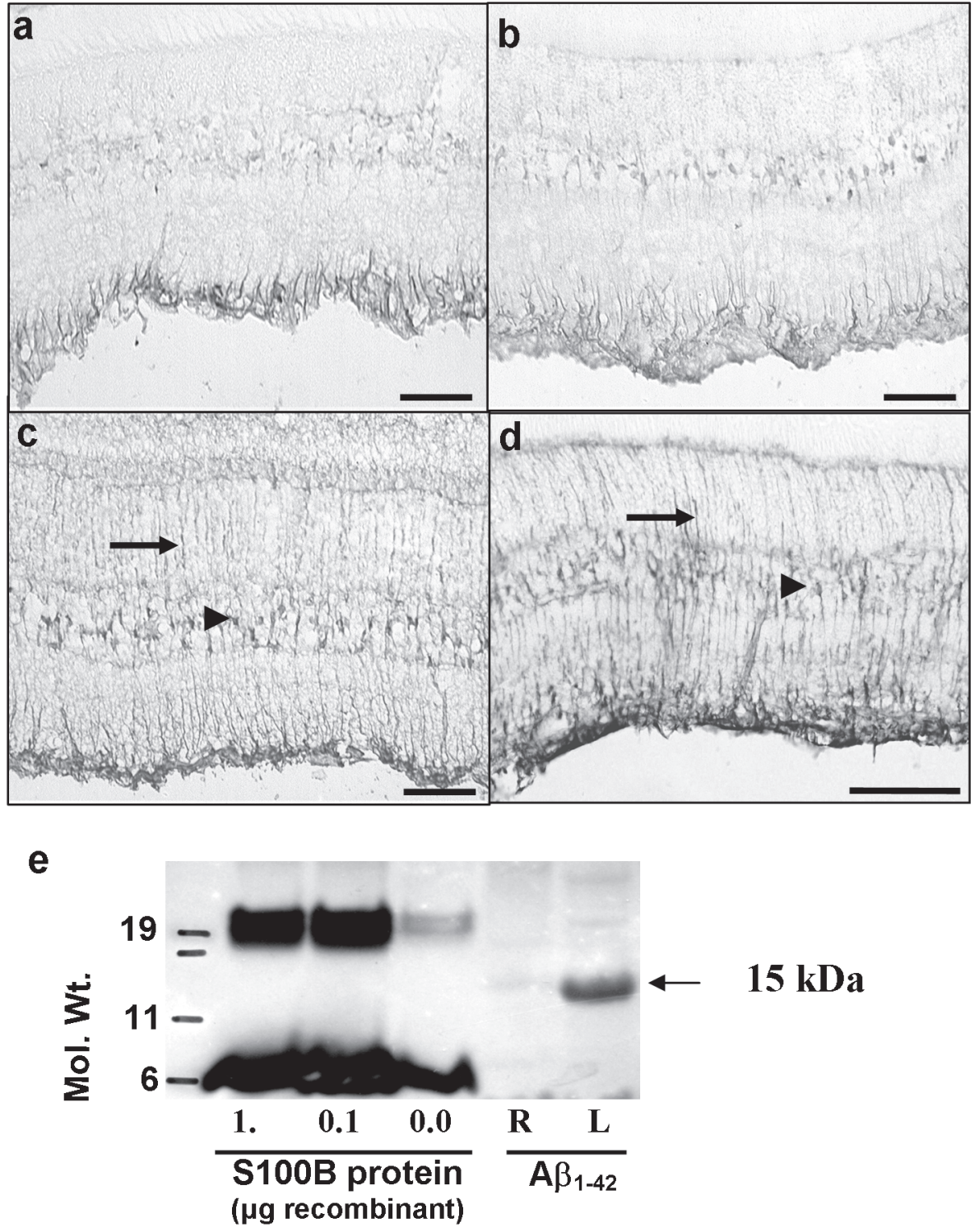

Figure $4 \mathrm{SIOOB}$ immunostaining in (a) noninjected rat retina shows that there is normal expression of the protein in the Müller cell endfeet. (b) SIO0B is only slightly increased after injection of PBS. (c) 2 days after injection of $A \beta_{1-42}$ there is a marked up-regulation of SI00B in the Müller cell endfeet, cell bodies (arrowhead) and processes (arrows) throughout the retina. (d) There was also a marked increase in SIOOB immunoreactivity 7 days after injection of IL-I $\beta$. (e) The increase in SI00B after A $\beta_{I-42}$ injection was confirmed by Western blotting. Recombinant bovine SIOOB is shown in lanes I-3 and forms two bands at 7 and $19 \mathrm{kDa}$. Injection of A $\beta_{1-42}$ caused strong expression of a single I $5 \mathrm{kDa}$ band in the injected left eye (L) compared with a comparatively weak expression in the noninjected, right eye (R).

Abbreviations: PBS, phosphate-buffer solution.

of the similarity in the retinal APP Western blot band pattern, it is likely that the same is happening here.

IL-1 $\beta$ has been shown to cause changes in APP levels in other cell systems in vitro. In U-373 MG astrocytoma cells, IL-1 $\beta$ caused an increase in $\alpha$ APPs (Gitter et al 2000), whilst in the PC12 cell line, IL-1 $\beta$ enhanced the secretion of N-terminal fragments of APP, again reflecting increased processing of APP (Dash and Moore 1995).

Our Western blots showed a greater reduction in the $54 \mathrm{kDa}$ band compared with the $98 \mathrm{kDa}$, especially after IL-1 $\beta$ injection (Figure 3a). It would appear that this band is more sensitive to the degradation process than the $98 \mathrm{kDa}$ band. Interestingly, this $54 \mathrm{kDa}$ band has also been identified in the neuromuscular junction, which, like the retina, is rich in cholinergic innervations (Dash and Moore 1995) and may imply that cholinergic innervation exerts some control over APP levels. It remains to be seen if the IL-1 $\beta$ - or $A \beta_{1-42}$-induced metabolism of APP yields amyloidogenic $A \beta_{1-42}$ in this in vivo model.

S100B induced a small decrease in APP-IR in the RGC (Figure $1 \mathrm{~g}$ and $\mathrm{h}$ ), though not as marked as with IL-1 $\beta$ (Figure 1c and d), suggesting that S100B may not be initiating such a severe response as the other mediator. However, 
we also noted the appearance of some large, intensely APP-IR cells within the retinal ganglion cell layer (Figure $1 \mathrm{~g}-\mathrm{j}$ ). This was accompanied by marked up-regulation the $98 \mathrm{kDa}$ APP holoprotein in the injected and noninjected eyes of rats treated with $\mathrm{S} 100 \mathrm{~B}$ as determined by Western blot (Figure 3b); that is, $\mathrm{S} 100 \beta$ induced a contralateral effect on APP biosynthesis. It may be that the increase in the APP levels in these large ganglion cells is masking the small loss of APP seen in IHC. The appearance of faint bands at approximately $30 \mathrm{kDa}$ and $37 \mathrm{kDa}$ in Figure $3 \mathrm{~b}$ might reflect a different APP metabolism to that produced by injection of $A \beta_{1-42}$.

To our knowledge, this is the first study that directly links $\mathrm{S} 100 \mathrm{~B}$ to increases in APP in vivo. S100B has been shown to cause an increase in APP protein and message in neurones from primary culture of rat foetal cortex ( $\mathrm{Li}$ et al 1998). At low doses, S100B promotes neurite outgrowth (Kligman and Marshak 1985) and enhances neuronal survival after injury and during development (Winningham-Major et al 1989). Given its role in axonal transport, the appearance of increased APP may indicate that that these cells are undergoing some aberrant sprouting/neuritic outgrowth. The observation of increased APP in a subset of projection neurons may have important implications in AD. Astrocytes over-expressing S100B have been found to correlate with the proliferation of dystrophic neurites over-expressing APP in the cortex and within plaques in AD patients (Mrak et al 1996) and here we provide direct evidence that $\mathrm{S} 100 \mathrm{~B}$ can induce increases in neuronal APP in an animal model. Interestingly, we noted the appearance of a small number of densely stained RGCs 7 days after the injection of IL- $1 \beta$. Our results show that an intravitreal injection of IL- $1 \beta$ causes a prolonged increase in S100B staining in Müller glia (Figure 4d) and exposure to $A \beta_{1-42}$ up-regulates retinal $S 100 \beta$ two days after injection (Figure 4c). This may suggest that IL-1 $\beta$-stimulated release of $\mathrm{S} 100 \mathrm{~B}$ is causing this delayed increase in cells over-expressing APP - an observation that warrants further investigation. The increase in S100B staining seen after IL$1 \beta$ and $A \beta_{1-42}$ seen here is similar to the increase in GFAP in Müller glia seen after $A \beta_{1-42}$ treatment (Bamford et al 1997; Walsh et al 2002), optic nerve crush, and intravitreal lipopolysaccharide injection (data not shown) and highlights that this response is not specific to any particular treatment and is a general marker of astrocytic activation. However, this raises the possibility that activation of glial cells, by whatever means, may exacerbate the disease progression.

Using a retinal-vitreal system, we have shown that intravitreal injection of either IL- $1 \beta$ or $A \beta_{1-42}$ induce a reduction in APP levels probably due to altered metabolism while S100B increased APP in a subset of neurons in a time-dependent fashion. We have also shown that both $A \beta_{1-42}$ and IL-1 $\beta$ up-regulate S100B itself. These changes may have important implications in the pathogenesis of AD. Both IL-1 $\beta$ and S100B have been shown to be associated with reactive astrocytes and dystrophic neurites over-expressing APP and here we provide in vivo evidence of a direct link between these mediators and APP production and metabolism. It has been hypothesised that in AD, a "cytokine cycle" may underlie the progression of the disease (Griffin et al 1998). In this cycle, within the environs of senile plaques, A $\beta$ and soluble APP cause the release of IL- $1 \beta$ from activated microglia. This in turn stimulates the release of S100B from astrocytes and has direct effects on APP levels in neurons. Our in vivo evidence suggests that $\mathrm{S} 100 \mathrm{~B}$ is secreted by glial Müller cells in the retina; that $\mathrm{S} 100 \mathrm{~B}$ is able to increase $\mathrm{APP}$ expression; and that both IL-1 $\beta$ and $A \beta_{1-42}$ increase the processing of APP. Our retinal-vitreal system functions as an ideal in vivo system to study the interplay between IL-1 $\beta, \mathrm{S} 100 \mathrm{~B}, \mathrm{~A} \beta$ and APP. Future work will determine the identities of the APP protein fragments seen in the Western blots published in this paper. It may be that the IL-1 $\beta$-S100B cytokine cycle described above, in up-regulating APP levels, leads to increased production of the fibrillogenic $\mathrm{A} \beta_{1-42}$ and the formation of amyloid plaques.

\section{Acknowledgments}

This work was supported by the American Alzheimer's Association (IRG-00-2441) and The National Institutes of Health (AG12411) and GlaxoSmithKline.

\section{References}

Akaaboune M, Allinquant B, Farza H, et al. 2000. Developmental regulation of amyloid precursor protein at the neuromuscular junction in mouse skeletal muscle. Mol Cell Neurosci, 15:355-67.

Bamforth SD, Lightman SL, Greenwood J. 1997. Interleukin-1 beta-induced disruption of the retinal vascular barrier of the central nervous system is mediated through leukocyte recruitment and histamine. Am J Pathol, 150:329-40.

Bhattacharyya A, Oppenheim RW, Prevette D, et al. 1992. S100 is present in developing chicken neurons and Schwann cells and promotes motor neuron survival in vivo. $J$ Neurobiol, 23:451-66.

Bresciani LG, Walsh DT, Gentleman SM, et al. 2002. Developmental regulation and possible alternative cleavage of presenilin 1 in the rat retina. Mol Cell Neurosci, 21:239-49.

Buxbaum JD, Oishi M, Chen HI, et al. 1992. Cholinergic agonists and interleukin 1 regulate processing and secretion of the Alzheimer beta/A4 amyloid protein precursor. Proc Natl Acad Sci USA, 89:10075-8.

Chen ST, Gentleman SM, Garey LJ, et al. 1996. Distribution of beta-amyloid precursor and B-cell lymphoma protooncogene proteins in the rat retina after optic nerve transection or vascular lesion. J Neuropathol Exp Neurol, 55:1073-82.

Chen ST, Jen A, Gentleman SM, et al. 1999. Effects of bFGF and TGFbeta on the expression of amyloid precursor and B-cell lymphoma protooncogene proteins in the rat retina. Neuroreport, 10:509-12. 
Ciallella JR, Ikonomovic MD, Paljug WR, et al. 2002. Changes in expression of amyloid precursor protein and interleukin-1beta after experimental traumatic brain injury in rats. $J$ Neurotrauma, 19:1555-67.

Croucher MJ, Patel H, Walsh DT, et al. 2003. Up-regulation of soluble amyloid precursor protein fragment secretion in the rat retina in vivo by metabotropic glutamate receptor stimulation. Neuroreport, 14:2271-4.

Dash PK, Moore AN. 1995. Enhanced processing of APP induced by IL-1 beta can be reduced by indomethacin and nordihydroguaiaretic acid. Biochem Biophys Res Commun, 208:542-8.

Donato R. 2001. S100: a multigenic family of calcium-modulated proteins of the EF-hand type with intracellular and extracellular functional roles. Int J Biochem Cell Biol, 33:637-68.

Gitter BD, Boggs LN, May PC, et al. 2000. Regulation of cytokine secretion and amyloid precursor protein processing by proinflammatory amyloid beta (A beta). Ann N Y Acad Sci, 917:154-64.

Goldgaber D, Harris HW, Hla T, et al. 1989. Interleukin 1 regulates synthesis of amyloid beta-protein precursor mRNA in human endothelial cells. Proc Natl Acad Sci USA, 86:7606-10.

Griffin WS, Sheng JG, Roberts GW, et al. 1995. Interleukin-1 expression in different plaque types in Alzheimer's disease: significance in plaque evolution. J Neuropathol Exp Neurol, 54:276-81.

Griffin WS, Sheng JG, Royston MC, et al. 1998. Glial-neuronal interactions in Alzheimer's disease: the potential role of a 'cytokine cycle' in disease progression. Brain Pathol, 8:65-72.

Guo QX, Chau RM, Yang SZ, et al. 1991. Development of choline acetyltransferase-immunoreactive neurons in normal and intracranially transplanted retinas in rats. Brain Res Dev Brain Res, 62:177-87.

Guo QX, Yu MC, Garey LJ, et al. 1992a. Development of parvalbumin immunoreactive neurons in normal and intracranially transplanted retinas in the rat. Exp Brain Res, 90:359-68.

Guo QX, Yang SZ, Liang CL, et al. 1992b. Tyrosine-hydroxylase-immunoreactive neurons in retinal transplants in the rat. Biol Signals, 1:46-56.

Hardy J. 1997. Amyloid, the presenilins and Alzheimer's disease. Trends Neurosci, 20:154-9.

Jen LS, Hart AJ, Jen A, et al. 1998. Alzheimer's peptide kills cells of retina in vivo. Nature, 392:140-1.

Kim SH, Smith CJ, Van Eldik LJ. 2004. Importance of MAPK pathways for microglial pro-inflammatory cytokine IL-1[beta] production. Neurobiol Aging, 25:431-9.

Kligman D, Marshak DR. 1985. Purification and characterization of a neurite extension factor from bovine brain. Proc Natl Acad Sci USA, 82:7136-9.
Li Y, Wang J, Sheng JG, et al. 1998. S100 beta increases levels of beta-amyloid precursor protein and its encoding mRNA in rat neuronal cultures. J Neurochem, 71:1421-8.

Morin PJ, Abraham CR, Amaratunga A, et al. 1993. Amyloid precursor protein is synthesized by retinal ganglion cells, rapidly transported to the optic nerve plasma membrane and nerve terminals, and metabolized. J Neurochem, 61:464-73.

Mrak RE, Sheng JG, Griffin WS. 1996. Correlation of astrocytic S100 beta expression with dystrophic neurites in amyloid plaques of Alzheimer's disease. J Neuropathol Exp Neurol, 55:273-9.

Mrak RE, Griffin WS. 2001. The role of activated astrocytes and of the neurotrophic cytokine S100B in the pathogenesis of Alzheimer's disease. Neurobiol Aging, 22:915-C22.

Sastre M, Dewachter I, Landreth GE, et al. 2003. Nonsteroidal antiinflammatory drugs and peroxisome proliferator-activated receptorgamma agonists modulate immunostimulated processing of amyloid precursor protein through regulation of beta-secretase. $J$ Neurosci, 23:9796-804.

Sheng JG, Mrak RE, Rovnaghi CR, et al. 1996. Human brain S100 beta and S100 beta mRNA expression increases with age: pathogenic implications for Alzheimer's disease. Neurobiol Aging, 17:359-63.

Sheng JG, Mrak RE, Bales KR, et al. 2000. Overexpression of the neuritotrophic cytokine S100beta precedes the appearance of neuritic beta-amyloid plaques in APPV717F mice. $J$ Neurochem, 74:295-301.

Walsh DT, Bresciani L, Saunders D, et al. 2005. Amyloid beta peptide causes chronic glial cell activation and neuro-degeneration after intravitreal injection. Neuropathol Appl Neurobiol, 31:491-502.

Walsh DT, Montero RM, Bresciani LG, et al. 2002. Amyloid-beta peptide is toxic to neurons in vivo via indirect mechanisms. Neurobiol Dis, 10:20-7.

Watts HR, Vince V, Walsh DT, et al. 2007. Alterations in presenilin 1 processing by amyloid-beta peptide in the rat retina. Exp Brain Res, 181:69-77.

Winningham-Major F, Staecker JL, Barger SW, et al. 1989. Neurite extension and neuronal survival activities of recombinant S100 beta proteins that differ in the content and position of cysteine residues. J Cell Biol, 109: 3063-71.

Yang SZ, Guo QX, Tsang D, et al. 1992. Development of gammaaminobutyric acid-immunoreactive neurons in normal and intracranially transplanted retinas in rats. Brain Res Bull, 28:543-50. 